Review Article

\title{
Probiotics Can Further Reduce Waist Circumference in Adults with Morbid Obesity after Bariatric Surgery: A Systematic Review and Meta-Analysis of Randomized Controlled Trials
}

\author{
Yu Zhang, ${ }^{1}$ Tong Yan, ${ }^{2}$ Chenxin Xu, ${ }^{1}$ Huawu Yang, ${ }^{3}$ Tongtong Zhang, ${ }^{4}$ and Yanjun Liu ${ }^{3}$ \\ ${ }^{1}$ The Affiliated Hospital of Southwest Jiaotong University, Chengdu, China \\ ${ }^{2}$ Department of Endocrinology and Metabolism, Affiliated Hospital of Southwest Jiaotong University, \\ The Third People's Hospital of Chengdu, Chengdu, China \\ ${ }^{3}$ The Center of Gastrointestinal and Minimally Invasive Surgery, Affiliated Hospital of Southwest Jiaotong University, \\ The Third People's Hospital of Chengdu, Chengdu, China \\ ${ }^{4}$ Medical Research Center, Affiliated Hospital of Southwest Jiaotong University, The Third People's Hospital of Chengdu, \\ Chengdu, China
}

Correspondence should be addressed to Yanjun Liu; liuyanjun_001@163.com

Received 5 January 2021; Revised 15 March 2021; Accepted 18 March 2021; Published 1 April 2021

Academic Editor: Amir Syahir

Copyright (c) $2021 \mathrm{Yu}$ Zhang et al. This is an open access article distributed under the Creative Commons Attribution License, which permits unrestricted use, distribution, and reproduction in any medium, provided the original work is properly cited.

Whether probiotics could be used as an adjunct to bariatric surgery is controversial. This meta-analysis aimed to evaluate the effects of probiotics on body weight, body mass index (BMI), percentage of the excess weight loss (\%EWL), waist circumference (WC), and C-reactive protein (CRP) in adults with obesity after bariatric surgery (BS). PUBMED, EMBASE, and the Cochrane Central Registry of Controlled Trials were searched from the earliest record to March 2020. All randomized controlled trials (RCTs) on the effects of probiotics in adults with obesity after bariatric surgery were analyzed according to the eligibility criteria. Four RCTs, including 172 participants, were analyzed. There was a statistically significant difference in probiotics in the reduction of waist circumference at 12 months after bariatric surgery. However, probiotics were not effective in weight, BMI, \%EWL, WC, and CRP both within 3 months and at 12 months postoperation. Probiotics aid adults with morbid obesity in achieving further waist circumference improvement after BS, with no significant effect on weight, BMI, \%EWL, and CRP. More quality clinical studies are needed to confirm the efficacy and safety of probiotics, and address a number of practical issues before the routine clinical use of probiotics in adults with obesity undergoing BS.

\section{Introduction}

Obesity is on the rise globally and multiplies the risk of metabolic diseases [1]. Bariatric surgery is an effective way to treat obesity and metabolic diseases, and one mechanism is to change the gut microbiome [2-4]. However, the beneficial changes in gut microbiota do not seem to be sustainable. The improvement of gut microbial gene richness following BS was showed to be partially restored in most patients, showed recently [5]. Moreover, deficiencies in micronutrients are common, while other disorders have also been reported, such as small intestinal bacterial overgrowth, weight regain, and abdominal symptoms [6-8]. These mean that additional strategies should be involved to improve further gut microbiota and clinical outcomes after BS.

The reversal effects on the host's obesity and metabolism issues promoted by modulators of intestinal microbiota, such as probiotics, have been successfully demonstrated. Probiotics were observed in animals to prevent and combat weight gain and improve obesity-related metabolic disorders, such as insulin resistance, disturbance of lipid metabolism, and reduction in systemic inflammation [9-12]. Some other evidence supports the potential modulating effects that probiotic supplements can reduce body weight and visceral fat mass $[13,14]$, as well as metabolic parameters in humans [15-17]. 
The clinical value of probiotic supplements as an adjunctive therapy among subjects with obesity undergoing BS was inconsistent. This systematic review and meta-analysis of randomized clinical trials aim to evaluate the adjuvant effect of probiotics on weight loss in patients with obesity after BS.

\section{Materials and Methods}

This systematic review and meta-analysis were prepared under the Preferred Reporting Items for Systematic Reviews and Meta-Analyses (PRISMA) guidelines [18].

2.1. Eligibility Criteria. Here are the inclusion criteria. (1) The study design was a randomized controlled clinical trial (RCT). (2) The participants were adults ( $\geq 18$ years) with obesity (body mass index $\geq 30 \mathrm{~kg} / \mathrm{m} 2$ ) and received any kind of bariatric surgeries. They also had short-term or long-term follow-up. (3) The study compared any type of probiotics or synbiotics (a combination of probiotics and prebiotics) with placebo [19]. (4) The study should have shown at least one of the following items: weight, body mass index (BMI), percentage of the excess weight loss (\%EWL), waist circumference (WC), and inflammatory factors.

Studies including patients who had undergone any other gastrointestinal surgeries were excluded. Also excluded were studies comparing probiotics with other interventions instead of placebo, as they also affect the outcomes.

2.2. Search Strategy. Two independent researchers searched the electronic databases of PUBMED, EMBASE, and the Cochrane Central Registry of Controlled Trials from the earliest record to 19 March 2020. Only studies published in the English language were considered. The following terms were used both as a medical subject heading (MeSH) and freetext terms: "Roux-en-Y gastric bypass," "sleeve gastrectomy," "bariatric surgery," "probiotics," and "synbiotics." Reference lists of each selected study were also searched by hand.

2.3. Data Extraction and Quality Assessment. The studies were selected by two independent researchers based on eligibility criteria. Extracted data involved author, publication year, country, study design, information of participants, intervention, and outcomes. The methodological quality within individual studies was also independently assessed by two researchers, via the Cochrane Collaboration's tool for judging the risk of bias in randomized trials [20]. Any disagreement was determined by discussion.

2.4. Statistical Analysis. This meta-analysis was accomplished via Review Manager (Version 5.3. Copenhagen: The Nordic Cochrane Centre, The Cochrane Collaboration, 2014). We pooled these data based on the duration of postoperational (less than 3 months or 12 months). All the outcomes in our meta-analysis were continuous variables, and standard mean differences (SMDs) with 95\% confidence intervals (CIs) were calculated using the mean changes (standard deviations) from baselines to estimate the pooled effects. If not provided explicitly, we calculated the missing standard deviations (SD) of the changes using the following formula suggested by the Cochrane Handbook [21]: SD2 $=$ SD baseline $2+$ SD final $2-(2 \times$ Corr $\times$ SD baseline $\times$ SD final). The correlation coefficient (Corr) was calculated by using sufficient data reported in the included studies and finally Corr $=0.6$. The pooled effect $p<0.05$ was regarded as statistically significant. The data unsuitable for quantitative analysis was limited to assess descriptively. We pooled these data based on the duration of post-operation (less than 3 months or 12 months).

The Chi2 test assessed heterogeneity, and the extent of heterogeneity was evaluated by the $I^{2}$ test. Chi2 test with $p<0.10$ and $I^{2}>50 \%$ indicated a significant degree of heterogeneity, and a random-effects model was used for analysis; otherwise, a fixed-effects model was applied. Publication bias was evaluated by the funnel plot, along with statistical estimates from Egger's test.

\section{Results}

3.1. Description of Included Studies. We used a PRISMA flowchart to present the process of study selection for this meta-analysis. A total of 1051 records were identified in the initial electronic search based on the eligibility criteria, and finally, only four randomized controlled trials [22-25], including 172 participants, met the selection criteria (Figure 1).

Table 1 presents the characteristics of these four studies. Weight, BMI, \%EWL, and WC were included as the primary outcomes. C-reactive protein (CRP), as one of the inflammatory factors with a significant positive correlation with obesity, was also included [26, 27]. We counted adverse events during these studies as well.

3.2. Risk of Bias. Figure 2(a) summarizes, as a table of judgements, each risk of bias item for included studies. Judgements about the risk of bias items across all are shown in Figure 2(b). Four trials had adequately described the method of randomization and assessed as quite a low risk of bias.

\subsection{Meta-Analysis Outcomes}

3.3.1. Weight. Among the 4 RCTs examined, two [22, 23] were included in the meta-analysis of the effect of probiotics on body weight within 3 months after bariatric surgery. One [22] showed a significant decrease in the probiotic arm, while the other [23] showed no change between two arms. Then, a meta-analysis pooling revealed no significant differences between the probiotics treatment group and the control group $(p=0.56)$, with a considerable heterogeneity between the studies $\left(p=0.006, I^{2}=87 \%\right)$ (Figure 3 ).

3.3.2. Body Mass Index (BMI). Three [22, 23, 25] of included trials provided outcomes of BMI, while two $[22,25]$ had postoperative 12-month follow-ups. Fernandes et al. [23] found that the placebo group declined significantly 


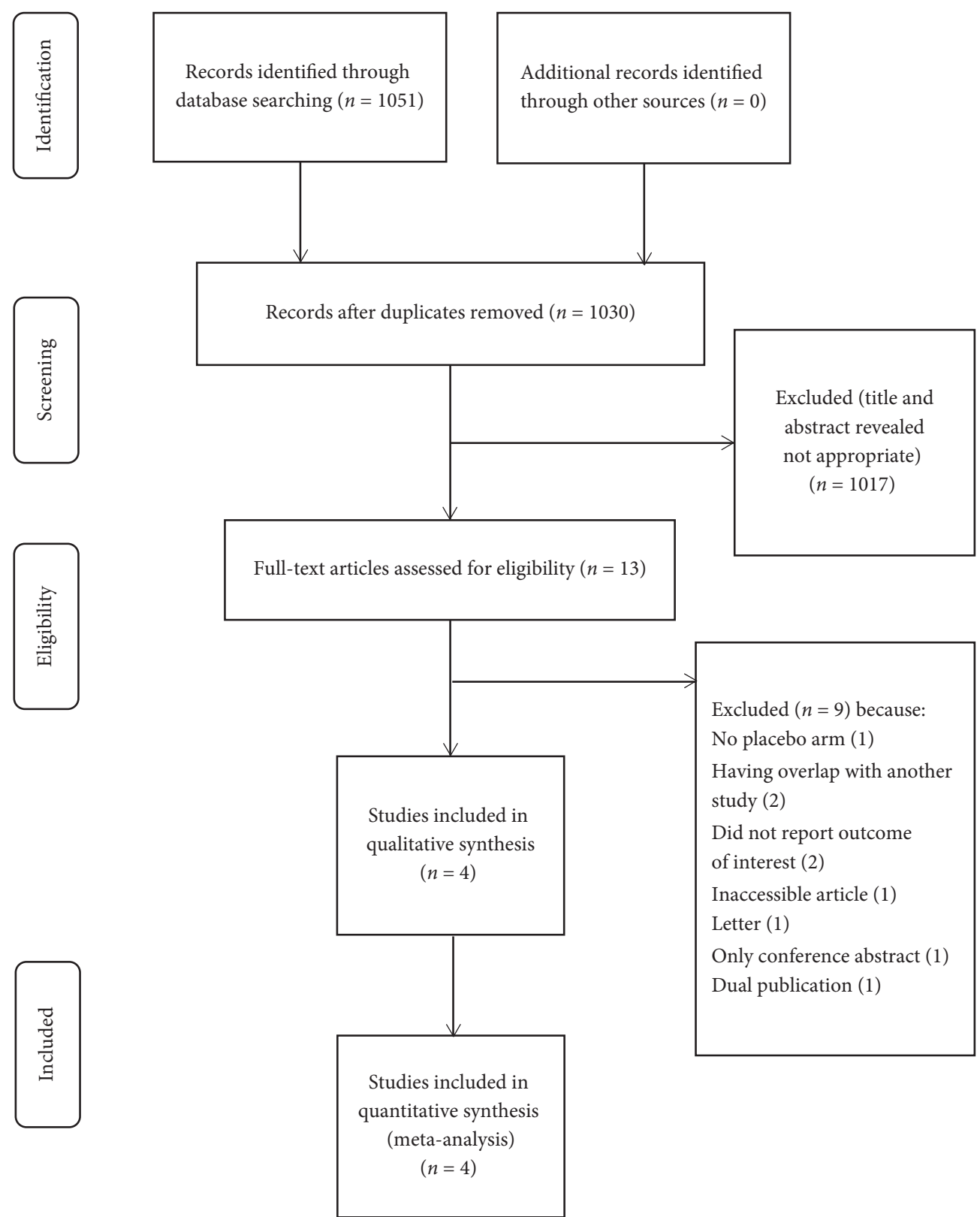

FIgURE 1: PRISMA flowchart of the process for searching and selecting studies.

TABLE 1: Characteristics of studies included in the meta-analysis.

\begin{tabular}{|c|c|c|c|c|c|c|}
\hline $\begin{array}{l}\text { Author } \\
\text { (year) }\end{array}$ & Country & $\begin{array}{l}\text { Study } \\
\text { design }\end{array}$ & Participants & $\begin{array}{l}\text { Intervention/ } \\
\text { control, BMI } \\
\left(\mathrm{kg} / \mathrm{m}^{2}\right)\end{array}$ & Intervention & $\begin{array}{c}\text { Analyzed } \\
\text { outcomes } \\
\text { included }\end{array}$ \\
\hline $\begin{array}{l}\text { Fernandes } \\
\text { et al. [23] }\end{array}$ & Brazil & $\begin{array}{l}\text { Parallel } \\
\text { RCT, } \\
\text { triple-blind }\end{array}$ & $\begin{array}{c}\text { Total } 6 \text { obese patients } \\
\text { undergoing RYGB (mean age } \\
\text { intervention } 36.7 \text { years, control } \\
32.0 \text { years) }\end{array}$ & $40.2 / 38.2$ & $\begin{array}{l}100 \mathrm{ml} \text { water containing } 6 \text { of } \\
\text { synbiotics* for } 15 \text { days }\end{array}$ & BMI, \%EWL \\
\hline $\begin{array}{l}\text { Mokhtari } \\
\text { et al. [22] }\end{array}$ & Iran & $\begin{array}{l}\text { Parallel } \\
\text { RCT, } \\
\text { double- } \\
\text { blind }\end{array}$ & $\begin{array}{c}\text { Total } 45 \text { obese patients } \\
\text { undergoing OAGB-MGB } \\
\text { (mean age intervention } 32.35 \\
\text { years, control } 36.95 \text { years) }\end{array}$ & $44.59 / 44.95$ & $\begin{array}{l}\text { Each capsule containing } 7 \\
\text { species of probiotics }^{* *} \text { for } 4 \\
\text { months }\end{array}$ & $\begin{array}{l}\text { BMI, \%EWL, } \\
\text { WC, CRP }\end{array}$ \\
\hline
\end{tabular}


TABle 1: Continued.

\begin{tabular}{|c|c|c|c|c|c|c|}
\hline $\begin{array}{l}\text { Author } \\
\text { (year) }\end{array}$ & Country & $\begin{array}{l}\text { Study } \\
\text { design }\end{array}$ & Participants & $\begin{array}{c}\text { Intervention/ } \\
\text { control, BMI } \\
\left(\mathrm{kg} / \mathrm{m}^{2}\right) \\
\end{array}$ & Intervention & $\begin{array}{c}\text { Analyzed } \\
\text { outcomes } \\
\text { included } \\
\end{array}$ \\
\hline $\begin{array}{l}\text { Sherf-dagan } \\
\text { et al. [25] }\end{array}$ & Israel & $\begin{array}{l}\text { Parallel } \\
\text { RCT, } \\
\text { double- } \\
\text { blind }\end{array}$ & $\begin{array}{c}\text { Total } 80 \text { obese patients } \\
\text { undergoing LSG (mean age } \\
\text { intervention } 42.1 \text { years, control } \\
44.2 \text { years) }\end{array}$ & $42.1 / 42.1$ & $\begin{array}{l}\text { Each capsule containing at } \\
\text { least } 25 \text { billion active bacteria } \\
(11 \text { species })^{* * *} \text { for } 6 \text { months }\end{array}$ & $\begin{array}{l}\text { BMI, \%EWL, } \\
\text { WC, CRP }\end{array}$ \\
\hline $\begin{array}{l}\text { Woodard } \\
\text { et al. [24] }\end{array}$ & USA & $\begin{array}{l}\text { Parallel } \\
\text { RCT, } \\
\text { double- } \\
\text { blind }\end{array}$ & $\begin{array}{c}\text { Total } 41 \text { obese patients } \\
\text { undergoing RYGB (mean age } \\
\text { intervention } 48.6 \text { years, control } \\
41.2 \text { years) }\end{array}$ & $45.7 / 49.6$ & $\begin{array}{c}\text { Each probiotic capsule } \\
\text { containing } 2.4 \text { billion live cells } \\
\text { of Lactobacillus species for } 6 \\
\text { months }\end{array}$ & $\%$ EWL \\
\hline
\end{tabular}

RCT: randomized controlled trial; RYGB: Roux-en-Y gastric bypass; OAGB-MGB: one-anastomosis gastric bypass; LSG: sleeve gastrectomy; FOS: fructooligosaccharide; BMI: body mass index; \%EWL: percentage of the excess weight loss; WC: waist circumference; CRP: C-reactive protein; *synbiotics: FOS $+1 \times 10^{9}$ Lactobacillus paracasei LPC- $37,1 \times 10^{9}$ Lactobacillus rhamnosus HN001, $1 \times 10^{9}$ Lactobacillus acidophilus NCFM, and $1 \times 10^{9}$ Bifidobacterium lactis HN019; placebo: maltodextrin; ${ }^{* *} 7$ species of probiotics: Lactobacillus casei $(3.5 \times 109$ CFU/g), Lactobacillus rhamnosus $(7.5 \times 108 \mathrm{CFU} / \mathrm{g})$, Streptococcus thermophiles $(1 \times 108 \mathrm{CFU} / \mathrm{g})$, Bifidobacterium breve $(1 \times 1010 \mathrm{CFU} / \mathrm{g})$, Lactobacillus acidophilus $(1 \times 109 \mathrm{CFU} / \mathrm{g})$, Bifidobacterium longum $(3.5 \times 109 \mathrm{CFU} / \mathrm{g})$, and Lactobacillus bulgaricus $(1 \times 108 \mathrm{CFU} / \mathrm{g})$ and $38.5-\mathrm{mg}$ fructo-oligosaccharide; placebo: maltodextrin; ${ }^{* * *} 11$ species of probiotics: Lactobacillus acidophilus, Bifidobacterium bifidum, Lactobacillus rhamnosus, Lactococcus lactis, Lactobacillus casei, Bifidobacterium breve, Streptococcus thermophiles, Bifdobacterium longum, Lactobacillus paracasei, Lactobacillus plantarum, and Bifidobacterium infantis; placebo: not provided; ${ }^{* * * *}$ placebo: not provided.

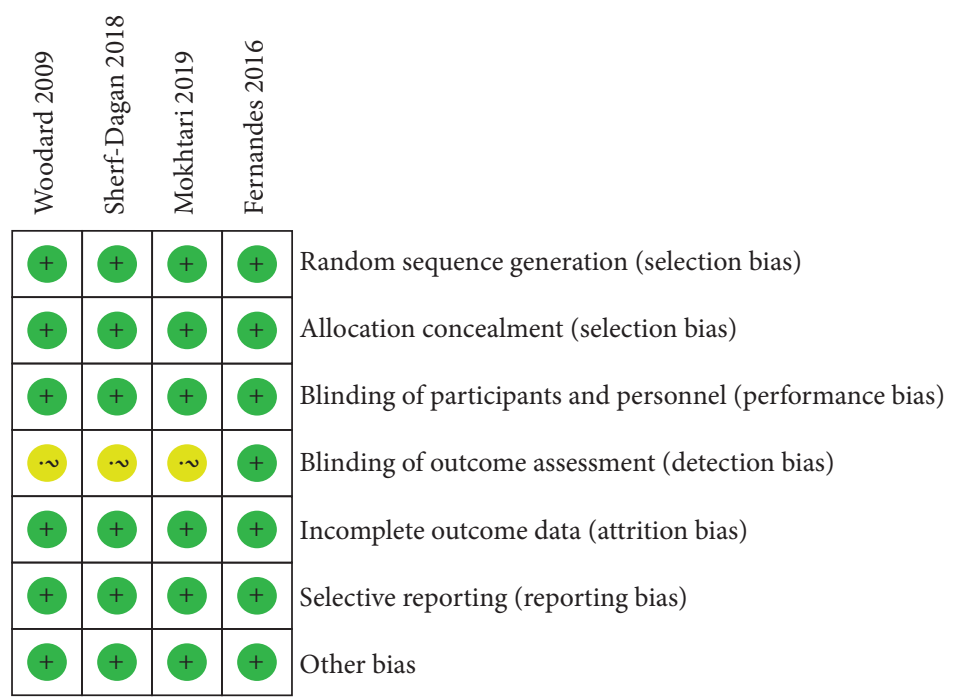

(a)

Random sequence generation (selection bias)

Allocation concealment (selection bias)

Blinding of participants and personnel (performance bias)

Blinding of outcome assessment (detection bias)

Incomplete outcome data (attrition bias)

Selective reporting (reporting bias )

Other bias

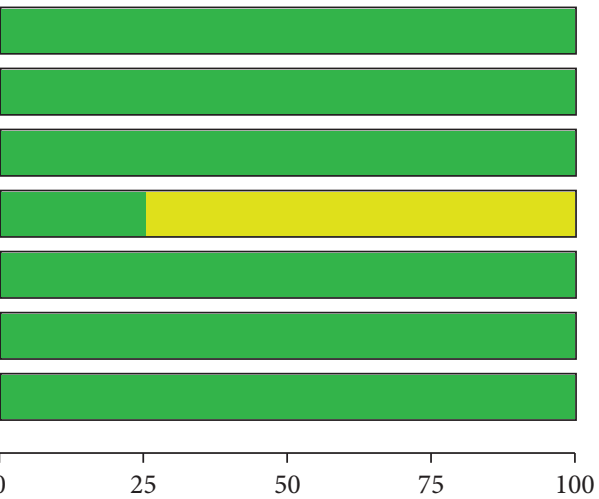

(\%)

Low risk of bias

Unclear risk of bias

High risk of bias

(b)

FIGURE 2: (a) Risk of bias summary: judgements about each risk of bias item for included studies. The green circle represents a low risk, and yellow represents an unclear risk, which means that no evidence was found. (b) Risk of bias graph: judgements about each risk of bias item presented as percentages across all included studies. The risk of bias is relatively low. 
compared with the synbiotic group at 15 days after BS. Mokhtari et al. [22] showed the advantage of the probiotic group in 3-month follow-up, but this advantage was not significant at 12 months. The outcomes in the study of SherfDagan et al. [25] were always without statistical difference. When the data were pooled for meta-analysis, there was no significant reduction in BMI following probiotic supplementation within 3-month follow-up $(p=0.99)$ with a huge heterogeneity $\left(p=0.01, I^{2}=77 \%\right.$ ) (Figure $4(\mathrm{a})$ ), and at 12 month follow-up $(p=0.68)$ without heterogeneity $\left(p=0.40, I^{2}=0 \%\right)$ (Figure $\left.4(\mathrm{~b})\right)$, respectively.

3.3.3. Percentage of the Excess Weight Loss (\%EWL). Among the four trials, two [22, 24] suggested statistically significant reductions in \%EWL within 3-month follow-up. At 12 months, only two [22, 25] of all selected studies were included with no statistical significance. A meta-analysis of all four trials also indicated no significant differences in \%EWL between the treatment group and the control group $(p=0.19)$ throughout a 3-month follow-up, whereas the support of interstudy heterogeneity was observed $\left(p=0.01, I^{2}=73 \%\right)$ (Figure 5(a)). At 12-month follow-up, the meta-analysis was also not significant $(p=0.93)$. The included studies were heterogeneous as well $\left(p=0.11, I^{2}=60 \%\right.$ ) (Figure 5(b)).

3.3.4. Waist Circumference (WC). Two [22, 25] studies reported on the changes in WC, and there did not seem to be a significant difference in the probiotic groups compared with the placebo. Only one study [22] reported a marginal statistical significance in $\mathrm{WC}$ decline in the probiotic group at 3 months. The pooled data indicated no significant differences in WC at 3 months after surgery $(p=0.39)$, with heterogeneity between the studies $\left(p=0.08, I^{2}=67 \%\right)$ (Figure 6(a)). However, at postoperative 12-month follow-up, the probiotic groups showed a statistically better effect on WC decline compared with the placebo $(p=0.007)$, with the included studies homogeneous $\left(p=0.39, I^{2}=0 \%\right)$ (Figure 6(b)).

3.3.5. C-Reactive Protein (CRP). Both included trials [22, 25] showed no statistically significant decrease in the probiotic group. The data pooled for analysis showed there was also no significant reduction in CRP between the probiotic and the placebo at 3 -month follow-up $(p=0.08)$ with a moderate heterogeneity $\left(p=0.17, I^{2}=46 \%\right)$ (Figure $\left.7(\mathrm{a})\right)$, and at 12 month follow-up $(p=0.52)$ with high heterogeneity $\left(p=0.11, I^{2}=61 \%\right)$ (Figure $\left.7(\mathrm{~b})\right)$, respectively.

3.4. Adverse Events. No studies reported severe adverse effects. One [23] reported that the patients developed excessive flatulence in the first 3 days of synbiotic supplementation, but no one dropped out of the study for this reason.

\section{Discussion}

This meta-analysis aimed to explore the adjunctive clinical effect of probiotics in obesity subjects after BS. We did not find meaningful evidence to suggest the benefit of probiotic supplements on weight, BMI, \%EWL, and CRP within 3 months and at 12 months after BS. However, we found a statistically significant effect on WC in patients with BS at 12-month follow-up, instead of 3 months after BS.

Our meta-analysis showed only a significant reduction of $-4.21 \mathrm{~cm}$ in WC for the probiotic group, instead of no effect on weight, \%EWL, BMI, and CRP. Several articles provided similar results in studies of people with obesity. A metaanalysis by Suzumura et al. [28] pooled data from nineteen RCTs, including 1412 overweight and adults with obesity, and reported that probiotic or synbiotic supplementation reduced $\mathrm{WC}$ with a limited effect $(\mathrm{MD}=-0.82 \mathrm{~cm})$, but no significant change in body weight or BMI. Similarly, a few RCTs demonstrated the positive impact of probiotics on WC in adults with obesity as well, but no significant effect on other indicators $[13,29]$. Moreover, the results were also observed in children and adolescents. A randomized, tripleblind trial conducted in 64 obesity children found WC decreased in the probiotic group, without significant change in weight and BMI [30]. WC, not BMI, is a crucial measure of the severity of obesity and is more closely associated with obesity-related metabolic diseases [31, 32]. Here is a unique phenomenon-probiotics that appeared to be able to alter fat distribution without changing the body's total weight in subjects with obesity undergoing BS, which is reflected only in the decline in WC-meaning that the use of probiotics seems to be more beneficial to patients with obesity and related metabolic diseases. However, these four articles included in the analysis did not collect the effects of probiotics on the relief of obesity-related metabolic diseases in patients with obesity after BS, and more RCTs are needed.

Some underlying mechanisms might explain the decline in WC. Certain probiotics are used to assist in the improvement of gut microbiota [33] and are involved in inhibiting the expression of adipogenesis and adipocyte differentiation-related genes in the host [34-36]. Recent studies suggest that probiotics regulate the expression of adipogenesis genes in the liver to reduce visceral adipose tissue [37, 38]. The decrease in abdominal fat accumulation is manifested as a decrease in WC. Otherwise, fecal shortchain fatty acids (SCFAs) were observed to increase after probiotic supplement [39]. SCFAs bind with $G$ proteincoupled receptors and affect the expression of intestinal hormones, which act with various insulin-sensitive tissues, which consequently leads to an improvement in obesity and a reduction in WC $[40,41]$.

We found no significant effect of probiotics on weight, BMI, \%EWL, and CRP in obesity undergoing BS. Possibly, BS has a massive impact on obesity and metabolism; hence, the minor role of probiotics is hidden. Meanwhile, some meta-analyses have also found the unavailability of probiotics in subjects with obesity [42-44]. Here are what we infer: (1) subjects essential characteristics. Overweight but not subjects with obesity were more likely to benefit from probiotic supplements $[45,46]$ because excessive fat accumulation is associated with more inferior metabolic disorders [47, 48]. The subjects of our included trials were morbidly obese, and may be it caused negative results. (2) Different gut microbial enterotype. Compared with the 


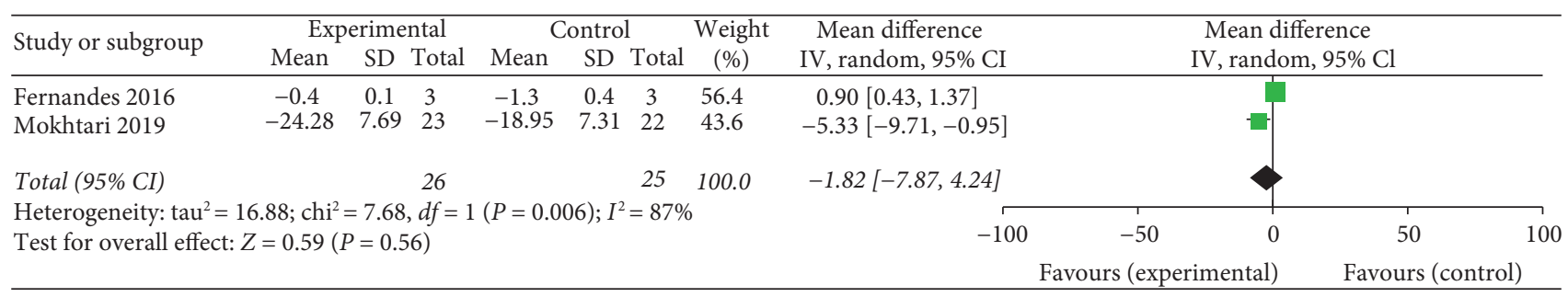

FIGURE 3: Forest plot presenting the effects of probiotic supplementation on the changes of weight in patients at 3 months after bariatric surgery.

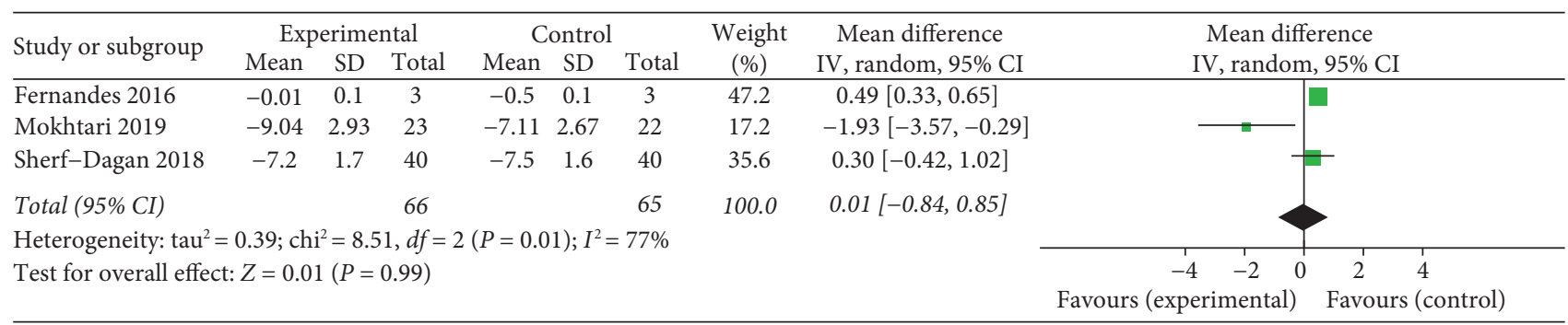

(a)

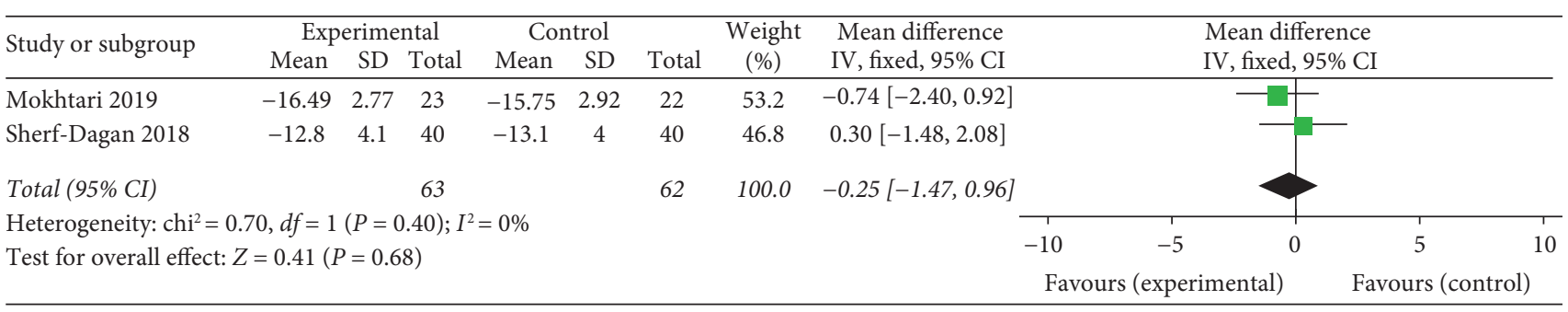

(b)

FIGURE 4: Forest plot presenting the effects of probiotic supplementation on the changes of BMI in patients at (a) 3 months and (b) 12 months after bariatric surgery, respectively.

\begin{tabular}{|c|c|c|c|c|c|c|c|c|c|c|c|}
\hline \multirow{2}{*}{ Study or subgroup } & \multicolumn{3}{|c|}{ Experimental } & \multicolumn{3}{|c|}{ Control } & \multirow{2}{*}{$\begin{array}{c}\text { Weight } \\
(\%)\end{array}$} & \multirow{2}{*}{$\begin{array}{c}\text { Mean difference } \\
\text { IV, random, 95\% CI }\end{array}$} & \multirow{2}{*}{\multicolumn{3}{|c|}{$\begin{array}{c}\text { Mean difference } \\
\text { IV, random, 95\% CI }\end{array}$}} \\
\hline & Mean & $\mathrm{SD}$ & Total & Mean & SD & Total & & & & & \\
\hline Fernandes 2016 & 23.7 & 5.1 & 3 & 22.3 & 6.1 & 3 & 21.4 & $1.40[-7.60,10.40]$ & \multicolumn{3}{|c|}{-1} \\
\hline Mokhtari 2019 & 46.82 & 12.69 & 23 & 36.34 & 12.66 & 22 & 24.4 & $10.48[3.07,17.89]$ & \multirow{2}{*}{\multicolumn{2}{|c|}{-}} & \\
\hline Sherf-Dagan 2018 & 43.7 & 10.2 & 40 & 45.7 & 11 & 40 & 29.9 & $-2.00[-6.65,2.65]$ & & & \\
\hline Woodard 2009 & 47.68 & 11.62 & 17 & 38.55 & 11.99 & 22 & 24.3 & $9.13[1.67,16.59]$ & \multicolumn{2}{|c|}{$\rightarrow-$} & \\
\hline Total (95\% CI) & & & 83 & & & 87 & 100.0 & $4.48[-2.18,11.14]$ & & & \\
\hline \multicolumn{12}{|c|}{ Heterogeneity: $\operatorname{tau}^{2}=32.99 ; \mathrm{chi}^{2}=11.08, d f=3(P=0.01) ; I^{2}=73 \%$} \\
\hline \multicolumn{8}{|c|}{ Test for overall effect: $Z=1.32(P=0.19)$} & -100 & -50 & 50 & 100 \\
\hline & & & & & & & & \multicolumn{2}{|c|}{ Favours (experimental) } & Favours & \\
\hline
\end{tabular}

(a)

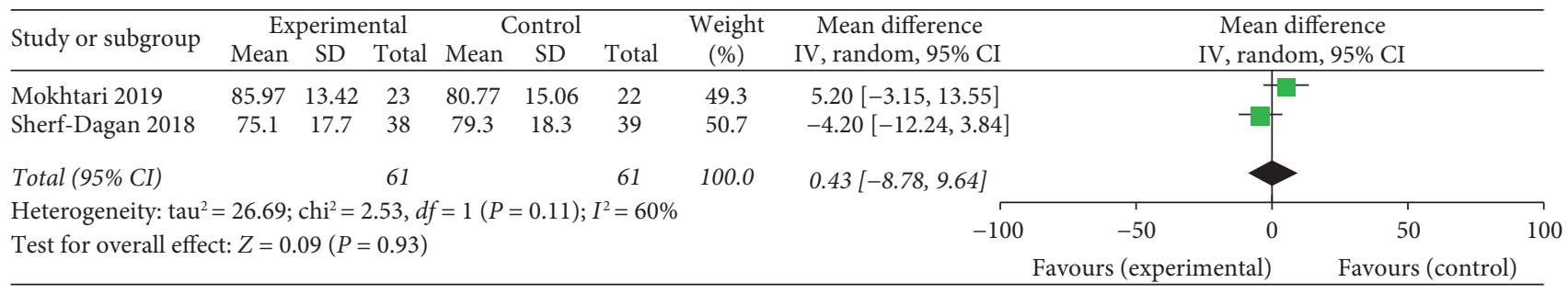

(b)

FIGURE 5: Forest plot presenting the effects of probiotic supplementation on the changes of \%EWL in patients at (a) 3 months and (b) 12 months after bariatric surgery, respectively. 


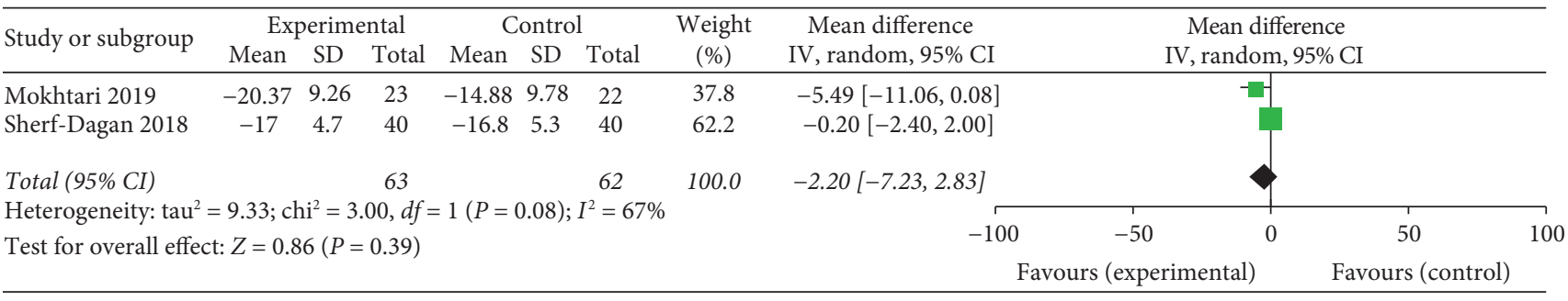

(a)

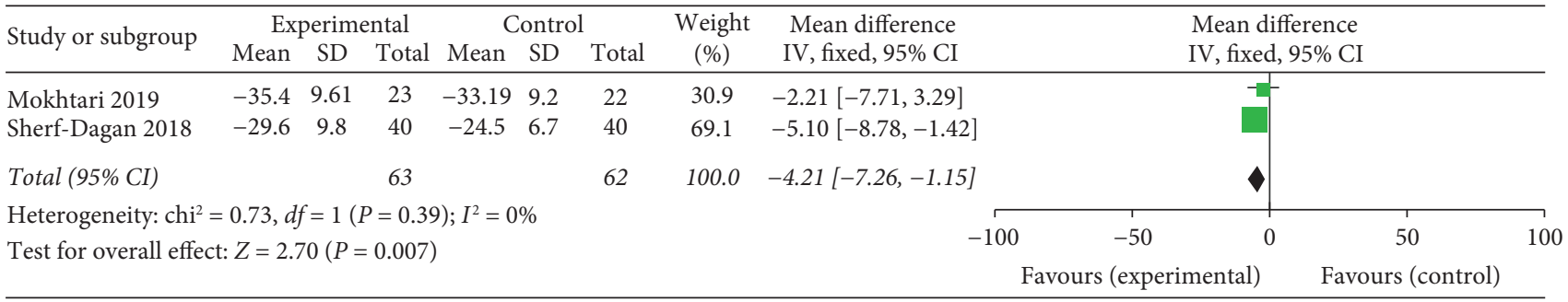

(b)

FIGURE 6: Forest plot presenting the effects of probiotic supplementation on the changes of WC in patients at (a) 3 months and (b) 12 months after bariatric surgery, respectively.

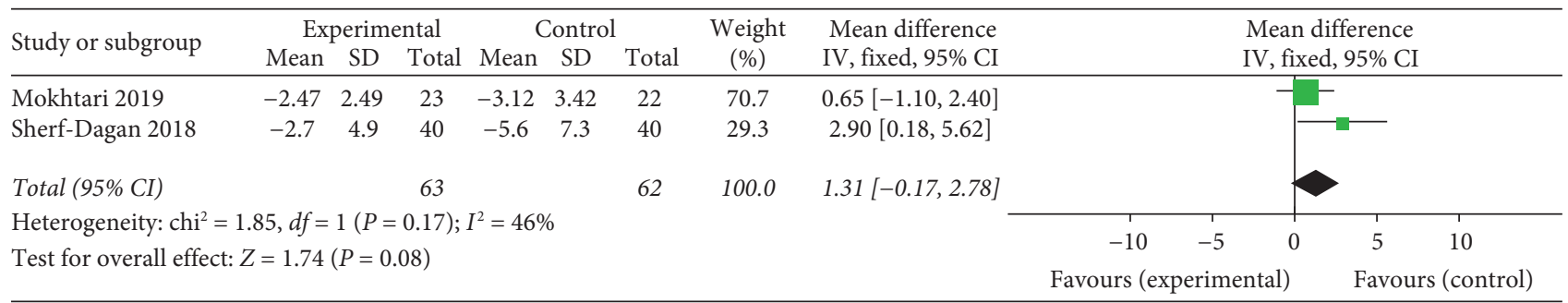

(a)

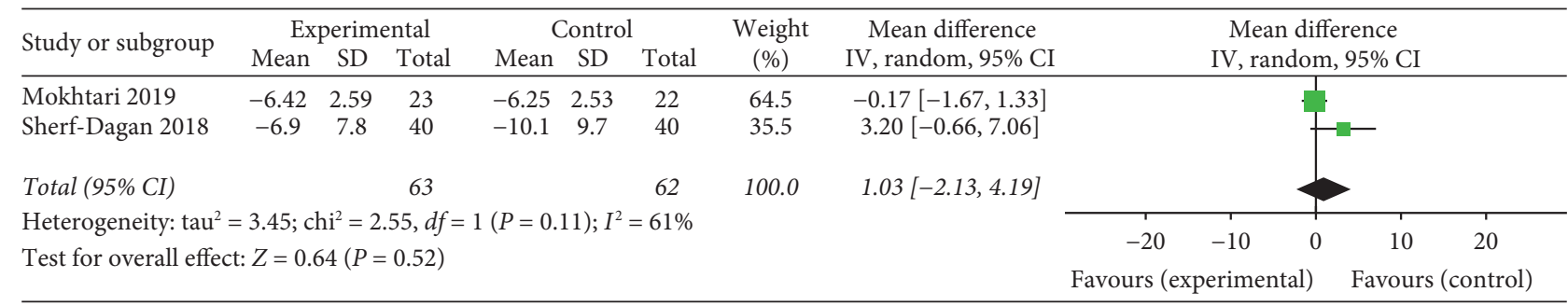

(b)

FIGURE 7: Forest plot presenting the effects of probiotic supplementation on the changes of CRP in patients at (a) 3 months and (b) 12 months after bariatric surgery, respectively.

Bacteroides-dominant enterotype, the Prevotella-dominant enterotype benefited more from probiotic supplements in the reduction of obesity-related markers, such as fat area and waist circumference [49]. (3) Type, dose, and duration of probiotic supplement. The probiotics consisting of multiple strains have significant effects, rather than a single strain [50]. High-dose probiotics appear to be more likely to affect gut microbiota and the host [13]. The longer intervention duration is associated with weight loss, inferring from several other meta-analyses [51, 52].

There are several strengths in this review. It is the first meta-analysis study on RCTs to explore the value of probiotics in the population with obesity undergoing BS.
Besides, we calculated the correlation coefficients for each group according to the guidelines in Cochrane's handbook, and change from baseline was selected as a practical value to reduce variability in subjects' status. Finally, we planned to group by follow-up time to minimize heterogeneity.

There are several limitations in this review. Although these 4 studies included were RCTs, we cannot make a decision for sure due to the too small sample size $(n=172)$. Shorter follow-up data were included (3 and 12 months after BS), which may have resulted in less significant results. In addition, we pooled data from up to three months for analysis, which further affected the results. Our review only covered patients with morbid obesity, and the conclusions 
cannot be directly extended to people with different levels of obesity. We did not assess subgroup analysis as well as publication bias due to the only four trials and the limited data included. Together, we need to evaluate the results carefully.

These four experiments had short follow-up time. Our meta-analysis found no change in WC at 3 months after probiotics use and a significant decrease at 12 months. This also suggests that we need to extend the follow-up time. During the four studies, the participants were not operated on the same BS. The structure of the gastrointestinal tract can be dramatically altered by different BS procedures, which may influence the interaction between probiotics and gut microbes. The type of participants was only morbid obesity, which may be a limitation for the use of probiotics in populations with obesity of varying degrees. Finally, the use of probiotics varied in these experiments.

Probiotics can assist BS to reduce WC in patients with morbid obesity, which optimizes the overall weight loss and metabolic outcomes. However, this review is only a preliminary exploration of probiotics in this field (assisting BS weight loss and improving metabolic disorders). Future clinical trials with larger samples and long-term interventions are needed to study the efficacy and safety. At the same time, probiotics specific to obesity and metabolic diseases should be further explored to determine whether they are commonly used in routine clinical use.

\section{Conclusions}

Probiotics aid adults with morbid obesity in achieving further waist circumference improvement after BS, but with no significant effect on weight, BMI, \%EWL, and CRP. More quality clinical studies are needed to confirm the efficacy and safety of probiotics and address a number of practical issues before the routine clinical use of probiotics in adults with obesity undergoing BS.

\section{Data Availability}

The data supporting the results of this study are available within the article.

\section{Conflicts of Interest}

The authors declare no conflicts of interest.

\section{Authors' Contributions}

All authors participated in the design of this analysis, data collection and analysis, paper writing, and revision.

\section{Acknowledgments}

The authors greatfully acknowledge the support of Sichuan Provincial Health and Family Planning Commission (18PJ504).

\section{References}

[1] M. Bluher, "Obesity: global epidemiology and pathogenesis," Nature Reviews Endocrinology, vol. 15, no. 5, pp. 288-298, 2019.

[2] T. E. Sweeney and J. M. Morton, "The human gut microbiome: a review of the effect of obesity and surgically induced weight loss," JAMA Surgery, vol. 148, no. 6, pp. 563-569, 2013.

[3] R. Liu, J. Hong, X. Xu et al., "Gut microbiome and serum metabolome alterations in obesity and after weight-loss intervention," Nature Medicine, vol. 23, no. 7, pp. 859-868, 2017.

[4] A. P. Liou, M. Paziuk, J. M. Luevano Jr., S. Machineni, P. J. Turnbaugh, and L. M. Kaplan, "Conserved shifts in the gut microbiota due to gastric bypass reduce host weight and adiposity," Science Translational Medicine, vol. 5, no. 178, Article ID 178ra141, 2013.

[5] J. Aron-Wisnewsky, E. Prifti, E. Belda et al., "Major microbiota dysbiosis in severe obesity: fate after bariatric surgery," Gut, vol. 68, no. 1, pp. 70-82, 2019.

[6] A. R. Schulman and C. C. Thompson, "Complications of bariatric surgery: what you can expect to see in your GI practice," American Journal of Gastroenterology, vol. 112, no. 11, pp. 1640-1655, 2017.

[7] J. Qiu, P. W. Lundberg, T. Javier Birriel, L. Claros, J. Stoltzfus, and M. El Chaar, "Revisional bariatric surgery for weight regain and refractory complications in a single MBSAQIP accredited center: what are we dealing with?" Obesity Surgery, vol. 28, no. 9, pp. 2789-2795, 2018

[8] B. S. Bal, F. C. Finelli, T. R. Shope, and T. R. Koch, "Nutritional deficiencies after bariatric surgery," Nature Reviews Endocrinology, vol. 8, no. 9, pp. 544-556, 2012.

[9] M. Mischke, T. Arora, S. Tims et al., "Specific synbiotics in early life protect against diet-induced obesity in adult mice," Diabetes, Obesity and Metabolism, vol. 20, no. 6, pp. 14081418, 2018.

[10] P. D. Cani, S. Possemiers, T. Van de Wiele et al., "Changes in gut microbiota control inflammation in obese mice through a mechanism involving GLP-2-driven improvement of gut permeability," Gut, vol. 58, no. 8, pp. 1091-1103, 2009.

[11] B. R. Choi, E. Y. Kwon, H. J. Kim, and M. S. Choi, "Role of synbiotics containing $\mathrm{d}$-allulose in the alteration of body fat and hepatic lipids in diet-induced obese mice," Nutrients, vol. 10, no. 11, 2018.

[12] W. Tunapong, N. Apaijai, S. Yasom et al., "Chronic treatment with prebiotics, probiotics and synbiotics attenuated cardiac dysfunction by improving cardiac mitochondrial dysfunction in male obese insulin-resistant rats," European Journal of Nutrition, vol. 57, no. 6, pp. 2091-2104, 2018.

[13] J. Kim, J. M. Yun, M. K. Kim, O. Kwon, and B. Cho, "Lactobacillus gasseri BNR17 supplementation reduces the visceral fat accumulation and waist circumference in obese adults: a randomized, double-blind, placebo-controlled trial," Journal of Medicinal Food, vol. 21, no. 5, pp. 454-461, 2018.

[14] E. Lau, J. S. Neves, M. Ferreira-Magalhaes, D. Carvalho, and P. Freitas, "Probiotic ingestion, obesity, and metabolic-related disorders: results from NHANES, 1999-2014," Nutrients, vol. 11, no. 7, 2019.

[15] M. Szulinska, I. Loniewski, S. van Hemert, M. Sobieska, and P. Bogdanski, "Dose-dependent effects of multispecies probiotic supplementation on the lipopolysaccharide (LPS) level and cardiometabolic profile in obese postmenopausal women: a 12-week randomized clinical trial," Nutrients, vol. 10, no. 6, 2018. 
[16] M. Szulinska, I. Loniewski, K. Skrypnik et al., "Multispecies probiotic supplementation favorably affects vascular function and reduces arterial stiffness in obese postmenopausal women-A 12-week placebo-controlled and randomized clinical study," Nutrients, vol. 10, no. 11, 2018.

[17] M. Mohammadi-Sartang, N. Bellissimo, J. O. Totosy de Zepetnek et al., "The effect of daily fortified yogurt consumption on weight loss in adults with metabolic syndrome: a 10-week randomized controlled trial," Nutrition, Metabolism and Cardiovascular Diseases, vol. 28, no. 6, pp. 565-574, 2018.

[18] L. Shamseer, D. Moher, M. Clarke et al., "Preferred reporting items for systematic review and meta-analysis protocols (PRISMA-P) 2015: elaboration and explanation," BMJ, vol. 350, Article ID g7647, 2015.

[19] M. De Vrese and J. Schrezenmeir, "Probiotics, prebiotics, and synbiotics," Advances in Biochemical Engineering/Biotechnology, vol. 111, pp. 1-66, 2018.

[20] J. P. Higgins, D. G. Altman, P. C. Gotzsche et al., "The Cochrane Collaboration's tool for assessing risk of bias in randomised trials," BMJ, vol. 343, Article ID d5928, 2011.

[21] J. P. T. Higgins and S. Green: Cochrane Handbook for Systematic Reviews of Interventions Version 5.1.0 2011. http:// www.cochrane-handbook.org.

[22] Z. Mokhtari, Z. Karbaschian, A. Pazouki et al., "The effects of probiotic supplements on blood markers of endotoxin and lipid peroxidation in patients undergoing gastric bypass surgery; a randomized, double-blind, placebo-controlled, clinical trial with 13 Months follow-up," Obesity Surgery, vol. 29, no. 4, pp. 1248-1258, 2019.

[23] R. Fernandes, B. T. Beserra, M. C. Mocellin et al., "Effects of prebiotic and synbiotic supplementation on inflammatory markers and anthropometric indices after roux-en-Y gastric bypass: a randomized, triple-blind, placebo-controlled pilot study," Journal of Clinical Gastroenterology, vol. 50, no. 3, pp. 208-217, 2016.

[24] G. A. Woodard, B. Encarnacion, J. R. Downey et al., "Probiotics improve outcomes after Roux-en-Y gastric bypass surgery: a prospective randomized trial," Journal of Gastrointestinal Surgery, vol. 13, no. 7, pp. 1198-1204, 2009.

[25] S. Sherf-Dagan, S. Zelber-Sagi, G. Zilberman-Schapira et al., "Probiotics administration following sleeve gastrectomy surgery: a randomized double-blind trial," International Journal of Obesity, vol. 42, no. 2, pp. 147-155, 2018.

[26] R. Weiss, J. Dziura, T. S. Burgert et al., "Obesity and the metabolic syndrome in children and adolescents," New England Journal of Medicine, vol. 350, no. 23, pp. 2362-2374, 2004.

[27] J. Choi, L. Joseph, and L. Pilote, "Obesity and C-reactive protein in various populations: a systematic review and metaanalysis," Obesity Reviews, vol. 14, no. 3, pp. 232-244, 2013.

[28] E. A. Suzumura, A. C. Bersch-Ferreira, C. R. Torreglosa et al., "Effects of oral supplementation with probiotics or synbiotics in overweight and obese adults: a systematic review and metaanalyses of randomized trials," Nutrition Reviews, vol. 77, no. 6, pp. 430-450, 2019.

[29] A. C. Gomes, R. G. de Sousa, P. B. Botelho, T. L. Gomes, P. O. Prada, and J. F. Mota, "The additional effects of a probiotic mix on abdominal adiposity and antioxidant Status: a double-blind, randomized trial," Obesity, vol. 25, no. 1, pp. 30-38, 2017.

[30] F. Famouri, Z. Shariat, M. Hashemipour, M. Keikha, and R. Kelishadi, "Effects of probiotics on nonalcoholic fatty liver disease in obese children and adolescents," Journal of Pediatric Gastroenterology \& Nutrition, vol. 64, no. 3, pp. 413-417, 2017.
[31] R. Ross, I. J. Neeland, S. Yamashita et al., "Waist circumference as a vital sign in clinical practice: a consensus statement from the IAS and ICCR working group on visceral obesity," Nature Reviews Endocrinology, vol. 16, no. 3, pp. 177-189, 2020.

[32] X. Hou, S. Chen, G. Hu et al., "Stronger associations of waist circumference and waist-to-height ratio with diabetes than BMI in Chinese adults," Diabetes Research and Clinical Practice, vol. 147, pp. 9-18, 2019.

[33] M. He and B. Shi, "Gut microbiota as a potential target of metabolic syndrome: the role of probiotics and prebiotics," Cell \& Bioscience, vol. 7, p. 54, 2017.

[34] D. Y. Park, Y. T. Ahn, C. S. Huh, S. M. Jeon, and M. S. Choi, "The inhibitory effect of Lactobacillus plantarum KY1032 cell extract on the adipogenesis of 3T3-L1 Cells," Journal of Medicinal Food, vol. 14, no. 6, pp. 670-675, 2011.

[35] Z. Zhang, Z. Zhou, Y. Li, L. Zhou, Q. Ding, and L. Xu, "Isolated exopolysaccharides from Lactobacillus rhamnosus GG alleviated adipogenesis mediated by TLR2 in mice," Scientific Reports, vol. 6, Article ID 36083, 2016.

[36] V. Sorrenti, C. L. Randazzo, C. Caggia et al., "Beneficial effects of pomegranate peel extract and probiotics on pre-adipocyte differentiation," Frontiers in Microbiology, vol. 10, p. 660, 2019.

[37] E. Lee, S. R. Jung, S. Y. Lee, N. K. Lee, H. D. Paik, and S. I. Lim, "Lactobacillus plantarum strain Ln4 attenuates diet-induced obesity, insulin resistance, and changes in hepatic mRNA levels associated with glucose and lipid metabolism," Nutrients, vol. 105 pages, 2018.

[38] W. J. Choi, H. J. Dong, H. U. Jeong et al., "Lactobacillus plantarum LMT1-48 exerts anti-obesity effect in high-fat dietinduced obese mice by regulating expression of lipogenic genes," Scientific Reports, vol. 10, no. 1, p. 869, 2020.

[39] Y. Lee, Z. Ba, R. F. Roberts et al., "Effects of Bifidobacterium animalis subsp. lactis BB-12((R)) on the lipid/lipoprotein profile and short chain fatty acids in healthy young adults: a randomized controlled trial," Nutrition Journal, vol. 16, no. 1, p. 39, 2017.

[40] M. A. G. Hernandez, E. E. Canfora, J. W. E. Jocken, and E. E. Blaak, "The short-chain fatty acid acetate in body weight control and insulin sensitivity," Nutrients, vol. 11, no. 8, 2019.

[41] Y. Lu, C. Fan, P. Li, Y. Lu, X. Chang, and K. Qi, "Short chain fatty acids prevent high-fat-diet-induced obesity in mice by regulating $\mathrm{G}$ protein-coupled receptors and gut microbiota," Scientific Reports, vol. 6, Article ID 37589, 2016.

[42] H. Mohammadi, A. Ghavami, A. Hadi, G. Askari, M. Symonds, and M. Miraghajani, "Effects of pro-/synbiotic supplementation on anthropometric and metabolic indices in overweight or obese children and adolescents: a systematic review and meta-analysis," Complementary Therapies in Medicine, vol. 44, pp. 269-276, 2019.

[43] A. Hadi, K. Alizadeh, H. Hajianfar, H. Mohammadi, and M. Miraghajani, "Efficacy of synbiotic supplementation in obesity treatment: a systematic review and meta-analysis of clinical trials," Critical Reviews in Food Science and Nutrition, vol. 60, no. 4, pp. 584-596, 2020.

[44] L. Liu, P. Li, Y. Liu, and Y. Zhang, "Efficacy of probiotics and synbiotics in patients with nonalcoholic fatty liver disease: a meta-analysis," Digestive Diseases and Sciences, vol. 64, no. 12, pp. 3402-3412, 2019.

[45] H. Koutnikova, B. Genser, M. Monteiro-Sepulveda et al., "Impact of bacterial probiotics on obesity, diabetes and nonalcoholic fatty liver disease related variables: a systematic 
review and meta-analysis of randomised controlled trials," BMJ Open, vol. 9, no. 3, Article ID e017995, 2019.

[46] D. R. Michael, A. A. Jack, G. Masetti et al., "A randomised controlled study shows supplementation of overweight and obese adults with lactobacilli and bifidobacteria reduces bodyweight and improves well-being," Scientific Reports, vol. 10, no. 1, p. 4183, 2020.

[47] J. B. Dowd and A. Zajacova, "Long-term obesity and cardiovascular, inflammatory, and metabolic risk in U.S. adults," American Journal of Preventive Medicine, vol. 46, no. 6, pp. 578-584, 2014.

[48] X. Hou, P. Chen, G. Hu et al., "Distribution and related factors of cardiometabolic disease stage based on body mass index level in Chinese adults-The National Diabetes and Metabolic Disorders Survey," Diabetes/Metabolism Research and Reviews, vol. 34, no. 2, 2018.

[49] E. J. Song, K. Han, T. J. Lim et al., "Effect of probiotics on obesity-related markers per enterotype: a double-blind, placebo-controlled, randomized clinical trial," EPMA Journal, vol. 11, no. 1, pp. 31-51, 2020.

[50] J. Sun and N. Buys, "Effects of probiotics consumption on lowering lipids and CVD risk factors: a systematic review and meta-analysis of randomized controlled trials," Annals of Medicine, vol. 47, no. 6, pp. 430-440, 2015.

[51] Q. Zhang, Y. Wu, and X. Fei, "Effect of probiotics on body weight and body-mass index: a systematic review and metaanalysis of randomized, controlled trials," International Journal of Food Sciences and Nutrition, vol. 67, no. 5, pp. 571-580, 2016.

[52] H. Borgeraas, L. K. Johnson, J. Skattebu, J. K. Hertel, and J. Hjelmesaeth, "Effects of probiotics on body weight, body mass index, fat mass and fat percentage in subjects with overweight or obesity: a systematic review and meta-analysis of randomized controlled trials," Obesity Reviews, vol. 19, no. 2, pp. 219-232, 2018. 